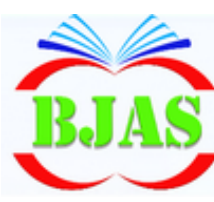

Available online at: http//bjas.bajas.edu.iq

College of Agriculture, University of Basrah

DOi:10.21276/basjas

ISSN 1814 - 5868

Basrah J. Agric. Sci., 32(Spec Issue): 217-227, 2019

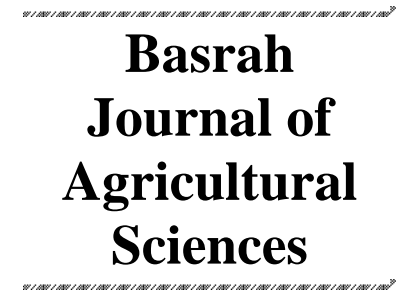

E-ISSN: 2520-0860

\title{
Physical and Functional Properties of Extracted Gum from Fenugreek Seeds
}

\author{
Bushra B. G. Al-Shammari*, Rawdhah M. A. Al-Ali \& Ali A. S. Al-Sahi \\ Department of Food Science, College of Agriculture, University of Basrah, Iraq. \\ *Corresponding author e-mail: bashra_bader@yahoo.com \\ Received 15 March 2019; Accepted 23 August 2019; Available online 18 September 2019
}

\begin{abstract}
The physical properties of extracted gum from Fenugreek seeds Trigonella foenum graccum L. were determined and compared with both Arabic and Acacia gums. The gum was extracted using water and precipitated with ethanol. There were a number of differences among gums regarding the $\mathrm{pH}$ value, density, refractive index and the wavelength. The $\mathrm{pH}$ value of the Fenugreek gum was 6.69 , while the lowest value was 5.02 in the Arabic gum. In contrast, the density of $1 \%$ Fenugreek gum was found to be 1.025 g.ml ${ }^{-1}$ compared with Arabic gum 1.0133 g.ml ${ }^{-1}$ and Acacia gum $1.0134 \mathrm{~g} \mathrm{ml}^{-1}$. The refractive index values were 1.3340, 1.3335 and 1.3336 for Fenugreek gum, Arabic gum, and Acacia gum, respectively. Moreover, the maximum wavelength of the Fenugreek seeds gum was at $330 \mathrm{~nm}$, while the results observed that both Arabic gum and acacia gum had the same wave length $(300 \mathrm{~nm})$. The functional properties of extracted Fenugreek gum were studied; the value of swelling Index was $90.90 \%$ compared to both Arabic gum (0.20\%) and Acacia gum $(0.20 \%)$. The solubility of the Fenugreek gum was $40 \%$ and $50 \%$ at $25^{\circ} \mathrm{C}$, and $80^{\circ} \mathrm{C}$, respectively. The results also showed that Fenugreek gum had high oil holding capacity value of $0.88 \%$ compared with the Arabic gum and Acacia gum. The Fenugreek gum was succeeded to form gels at $4^{\circ} \mathrm{C}$ using concentration $1,2,3$ and $4 \%$, while the Arabic gum and Acacia gum did not form gel at different concentrations.
\end{abstract}

Keywords: Fenugeek seeds gum, The physical parameters, Solubility, gel, Swelling index.

\section{Introduction}

Fenuqreek gum was produced from Fenuqreek seeds of Tniqonella Foenum graecum L. (Family: Lequminoella) and was cultivated in warm climates such as India. The Mediterranean weather may be successfully enabled to grow crops due to comparable daylight exposure (Robert et al., 2012). It is an old cultivated spice bean crop in India, Middle East, Southern Europ, North
Africa, and North America (Mundhe et al., 2012); it is one of the oldest cultivated plants and used in many applications such as food additives and traditional medicines. Fenugreek seeds contain a high percentage of gum which is mainly composed of galactomannan. The galactomannan is polysaccharides composed of linear $\beta-,(1-4)$ D- mannan backbone with varying amounts 
of single $\mathrm{D}$-galactose units attached to the main backbone by $\alpha$-(1-6) glycosides bond (Repin, 2016). It does not partially soluble in water and form a viscous tacky mass when exposed to fluids (Kumar et al., 2009); the gum is most commonly used in various pharmaceutical properties such as binding, gelling agent, emulsifying and suspending agent. In addition, it was used in baking, bread making, graries and soup (Kay, 2016; Repin, 2016). It has been extensively used in the pharmaceutical industry as binder, gelling agent, emulsifier and suspending (Mundhe et al., 2012) .

The aim of this research was to study the physical and functional properties of extracted gum from fenugreek seeds regarding the $\mathrm{pH}$, refractive index, wavelength, density, swelling index, solubility, gelation and oil holding capacity.

\section{Material \& Methods}

The seeds were purchased from local market of Basrah province. The seeds were gringing using a coffee grinder. Arabic gum and Acacia were obtained from the chemical BDH company, England. All the other solvent reagents and chemical used were analytical grade.

\section{Extraction of gum}

The gum was extracted according to the method described by Nazni \& Vigneshwar (2014). The fenugreek powder was soaked in distilled water within a ratio $(1: 10 \mathrm{w} / \mathrm{v})$, then kept under shaking for $4 \mathrm{~h}$ at $40{ }^{\circ} \mathrm{C}$. The viscous solution was filtered through muslin to remove the fibers. Ethanol (99\%) was added in the ratio $1: 1$ to precipitate out the gum present. The gum was dried in oven at temperature $40-45{ }^{\circ} \mathrm{C}$. The dried gum was stored in airtight container.
Physico-chemical characterization of the Fenugreek seed gum compared with Arabic and Acacia gums.

\section{pH}

One gram of gum was weighed in a beaker and mixed with $100 \mathrm{ml}$ of distilled water. The suspension was stirred for 5 minutes and the $\mathrm{pH}$ was measured using $\mathrm{pH}$ meter at $25^{\circ} \mathrm{C}$ according to the method described by Farooq et al. (2015).

\section{Determination of density and specific gravity}

The density of $1 \%$ of gums solutions was determined at $25^{\circ} \mathrm{C}$ according to Yusuf (2011).

\section{Refractive index}

The refractive index of $1 \%$ of the gums solutions was measured at $25^{\circ} \mathrm{C}$ using Abbe refractometer according to the method described by Gashua et al. (2013).

\section{The maximum wavelength}

The maximum wavelength of gum was determined using an ultraviolet -visible spectrophotometer at range of 200-800 nm according to the method described by Al-Janabi \& Al- Abdullah (2013).

\section{Swelling index}

The Swelling index was determined according to the method described by Verma et al. (2014). One gram of fenugreek gum powder was weighed and transferred in to the plastic centrifuge tube. The mixture was shaken thoroughly every $10 \mathrm{~min}$ for $1 \mathrm{hr}$ and then allowed to stand for $24 \mathrm{hrs}$ at the room temperature.

The Swelling index of the gum was calculated using the equation 


$$
\text { Swelling Index }(\%)=\frac{\text { Final Volume }- \text { lnitial volume }}{\text { final volume }}
$$

\section{Solubility}

Solubility was determined according to Amid \& Mirhosseini (2012). $1.0 \mathrm{~g}$ of gum powder was added to $100 \mathrm{ml}$ of distilled water with stirring at room temperature, then the temperature was raised to $80^{\circ} \mathrm{C}$ for $30 \mathrm{~min}$. After that, the gum solution was centrifuged at $6000 \mathrm{~g}$ for $30 \mathrm{~min}$ to remove the insoluble material. The settled portion was then transferred to a petri dish and dried at $105^{\circ} \mathrm{C}$ for $24 \mathrm{hrs}$.

The following equation was used to determine the solubility.

Solubility $(\%)=\mathrm{C}_{1} / \mathrm{C}_{2} \times 100$

Where $\mathrm{C} 1$ is the supernatant concentration $(\mathrm{mg}) \mathrm{C}_{2}$ is the Initial concentration (mg).

\section{Determination of Gelation}

The dry gum 1-10 gm dissolved in $100 \mathrm{ml}$ of water distilled and then the solutions were kept overnight at $4{ }^{\circ} \mathrm{C}$. The formation of gel and their quality was assessed by visual inspection according to Chidewe (2004).

\section{Effect of temperature}

The gums 1-10\% were incubated in a water bath at temperature range $4-100^{\circ} \mathrm{C}$. The Vials were allowed to stand overnight at $4^{\circ} \mathrm{C}$.

\section{Effect of PH on the formation of the gel.}

Citrate buffer was used between $\mathrm{pH} 3$ and 6 , while phosphate buffer was used at $\mathrm{pH} 7$ and Tris- $\mathrm{HCl}$ was used at $\mathrm{pH} 10$. The dry gum $1-10 \mathrm{~g}$ was dissolved in $10 \mathrm{ml}$ of buffer and the mixtures were allowed to stand overnight at $4 \mathrm{C}^{\circ}$ before assessment of gel Formation.

\section{Effect of Calcium Chloride on the formation} of the gel.

The gum 1-10\% was dispersed in the solution containing calcium chloride at concentration 0.5 $-20 \mathrm{Mm}$. The Suspension was allowed to stand overnight at $4^{\circ} \mathrm{C}$ before assessment of gel

\section{Effect of EDTA on the formation of the gel.}

EDTA was dissolved in distilled water to make solutions of concentration 10-50 mM. The gum $1-10 \%$ was Suspensions were allowed to be stand overnight at $4^{\circ} \mathrm{C}$ before assessment of gel formation.

\section{Oil - holding capacity}

The oil holding Capacity was determined according to Thanatcha \& Pranee, (2011). $0.5 \mathrm{~g}$ of the gum was dispersed in $10 \mathrm{ml}$ of sunflower oil and mixed using vortex Stirrer for $1 \mathrm{~min}$, then kept at room temperature for $30 \mathrm{~min}$ and centrifuged at $10000 \mathrm{~g}$ for 30 mins. The oil gum was weight and calculated by the following equation:

$$
\text { Oil Absorption }\left(\mathrm{g} \text { oil.g gum }{ }^{-1}\right)=\frac{\text { oil absorbed sample weight }- \text { Dry sample weight }}{\text { Dry sample weight }}
$$

\section{Statistical Analysis}

All the data of physical and functional properties with three replicates were analyzed using SPSS 2012. The comparative analysis between parameters was carried out using L.S.D. with probability $(\mathrm{P}<0.05)$.

\section{Results \& Discussion}

The results showed in Table 1 indicate that the $\mathrm{pH}$ of $1 \%$ fenugreek gum was 6.69 which was neutral because it contained neutral sugars, while the Arabic gum and Acacia were 5.02 and 5.19, respectively. The acidity of gum was due to uronic acids in their structure (Yusf, 2011). 
Table (1): The physical properties of gums.

\begin{tabular}{cccc}
\hline Para meter & Fenugreek seeds gum & Arabic gum & Acacia gum \\
\hline $\mathrm{pH}$ & $6.69 \mathrm{a}$ & $5.02 \mathrm{~b}$ & $5.19 \mathrm{~b}$ \\
\hline Density $\left(\mathrm{g} \cdot \mathrm{ml}^{-1}\right)$ & $1.025 \mathrm{a}$ & $1.0133 \mathrm{~b}$ & $1.0134 \mathrm{~b}$ \\
\hline Specific gravity & $1.0373 \mathrm{a}$ & $1.0255 \mathrm{~b}$ & $1.0256 \mathrm{~b}$ \\
\hline Refractive Index & $1.3340 \mathrm{a}$ & $1.3335 \mathrm{~b}$ & $1.3336 \mathrm{~b}$ \\
\hline
\end{tabular}

Means within the same parameter having different letters are significantly different $(P<0.05)$

The result was in agreement with Kumar et al. (2014). The Fenugreek gum exhibited a high refractive index (1.3340) compared to the Arabic gum (1.3335) and Acacia (1.3336). The results were not in agreement with Gashua et al. (2013). The result also revealed that the Fenugreek gum had a higher density $1.025 \mathrm{~g} \cdot \mathrm{ml}^{-1}$ and specific gravity of 1.0373 than the density and specific gravity of the Arabic gum and acacia gum of 1.0133, 1.0134 g.ml ${ }^{-1}$ and 1.0255, 1.0256, respectively.

Fig. (1) represents the maximum wave length of the Fenugreek seeds gum, Arabic gum and acacia gum. The results showed that the maximum wave length of $330 \mathrm{~nm}$ for the Fenugreek gum, while the wave length of Acacia and Arabic gum were 300 and $300 \mathrm{~nm}$, respectively. These differences may attribute to the nature and chemical composition of gums (AlJanabi \& Al-Abdullah , 2013).

According to the statistical analyses, the swelling index value of Fenugreek gum was significant $(\mathrm{P}<0.05)$ compared to a standard Arabic gum and Acacia (Fig. 2). The Fenugreek gum had high swelling index, the swelling coefficient depends on the size and distribution of the gum particles.

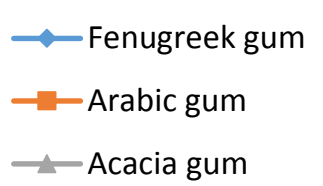

- Acacia gum

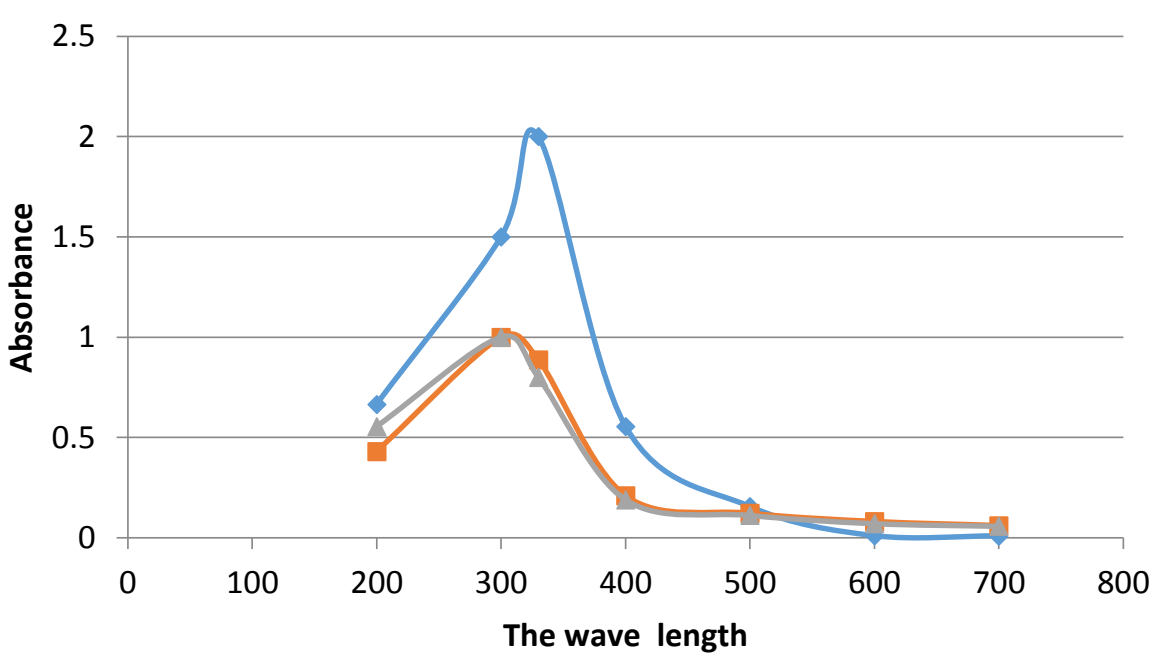

Fig. (1): The maximum wave length of plant gums. 


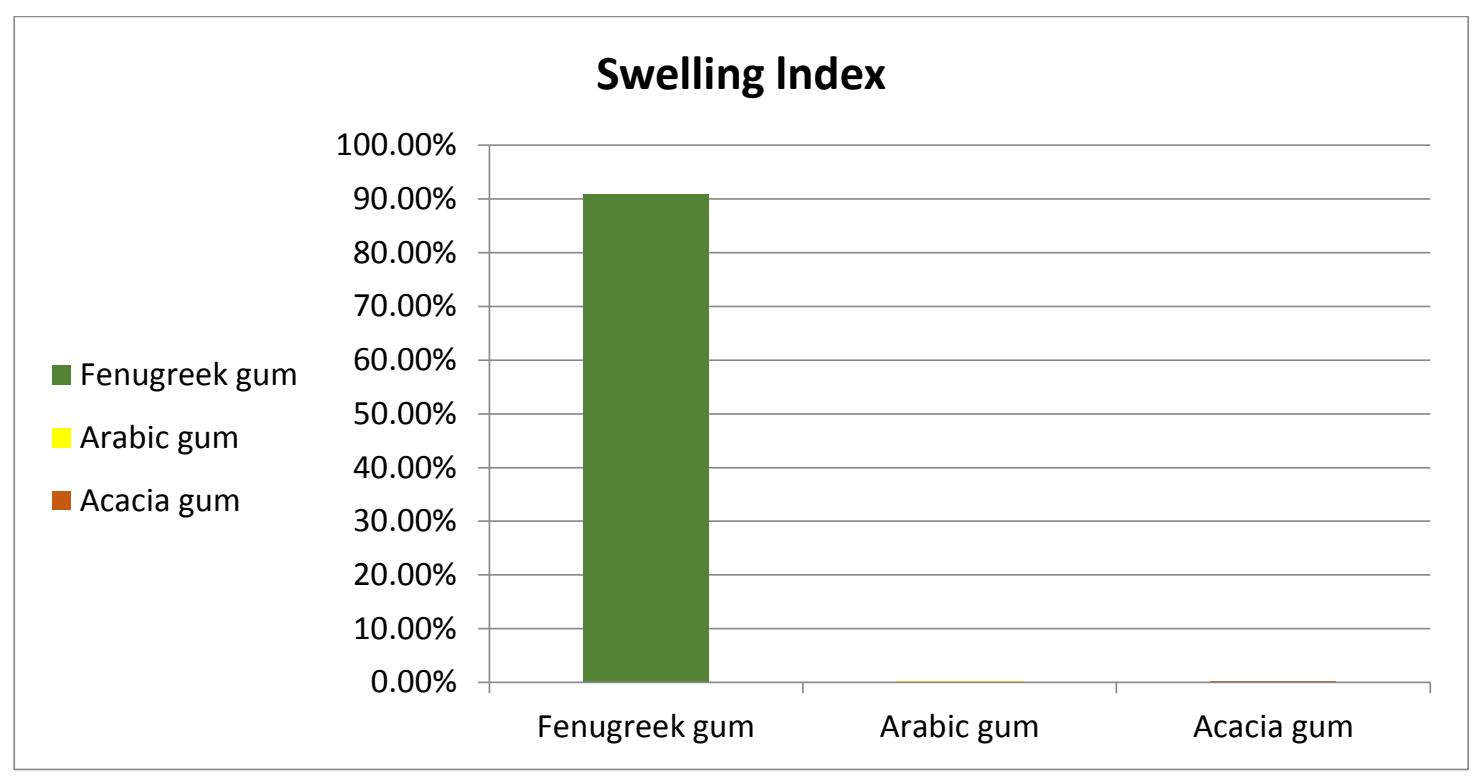

Fig. (2): The swelling index of three different plant gum $(\mathbf{P}<0.05)$.

The gum, which has a soft structural with many small pores, produces a high swelling coefficient and greater water relention compared to the gum containing large pores such arabic gum and Acacia, another reason was attributed to the nonpolar group in crude gum cause high swelling index (Amid \& Mirhossieni, 2012). In the research, The fenugreek gum may have afiner uniform gum structure than standard Arabic gum and Acacia. The result was agreement with Verma et al. (2014).

The results presented in Figs. ( $3 \& 4)$ indicate the solubility of gums increased as the temperature values increase at $25^{\circ} \mathrm{C}$ and $80^{\circ} \mathrm{C}$. The solubility of Fenugreek gum was significantly $(\mathrm{P}<0.05)$ lower at $25^{\circ} \mathrm{C}$ with average of $40 \%$, whereas the highest solubility at $80^{\circ} \mathrm{C}$ was $50 \%$. The solubility values for each of the Arabic gum and Acacia were recorded $90 \%$ at $25^{\circ} \mathrm{C}$, and were increased to $100 \%$ at $80^{\circ} \mathrm{C}$. The solubility is affected by several factors not only the content of galactose but also the type and content of the impurities, as well as the size and weight of molecules. The low solubility of crude gum is associated with the presence of the impurities and high molecular weight of molecules and insoluble matter. The solubility is affected by ratio of mannose to galactose and galactose distribution along the straight mannose chains, when reduced the content of galactose increased solubility at high temperature and the solubility was decreased at low temperature, and on the other hand; break the hydrogen bond between the polysaccharide chains and the emergence of hydroxyl group to water at high temperature, leading to improved solubility (Sciarini et al., 2009; Amid \& Mirhossieni, 2012). A similar observation was made by Bilal et al. (2015) indicating the solubility of raw and refined Arabic gum was increased as the temperature values increasing from $25^{\circ} \mathrm{C}$ to $100^{\circ} \mathrm{C}$. Amid \& Mirhosseini (2012) reported the increasing solubility of the raw and refined durian gum as the temperature was increased. 
Al-Shammari et al. / Basrah J. Agric. Sci., 32 (Special Issue): 217-227, 2019

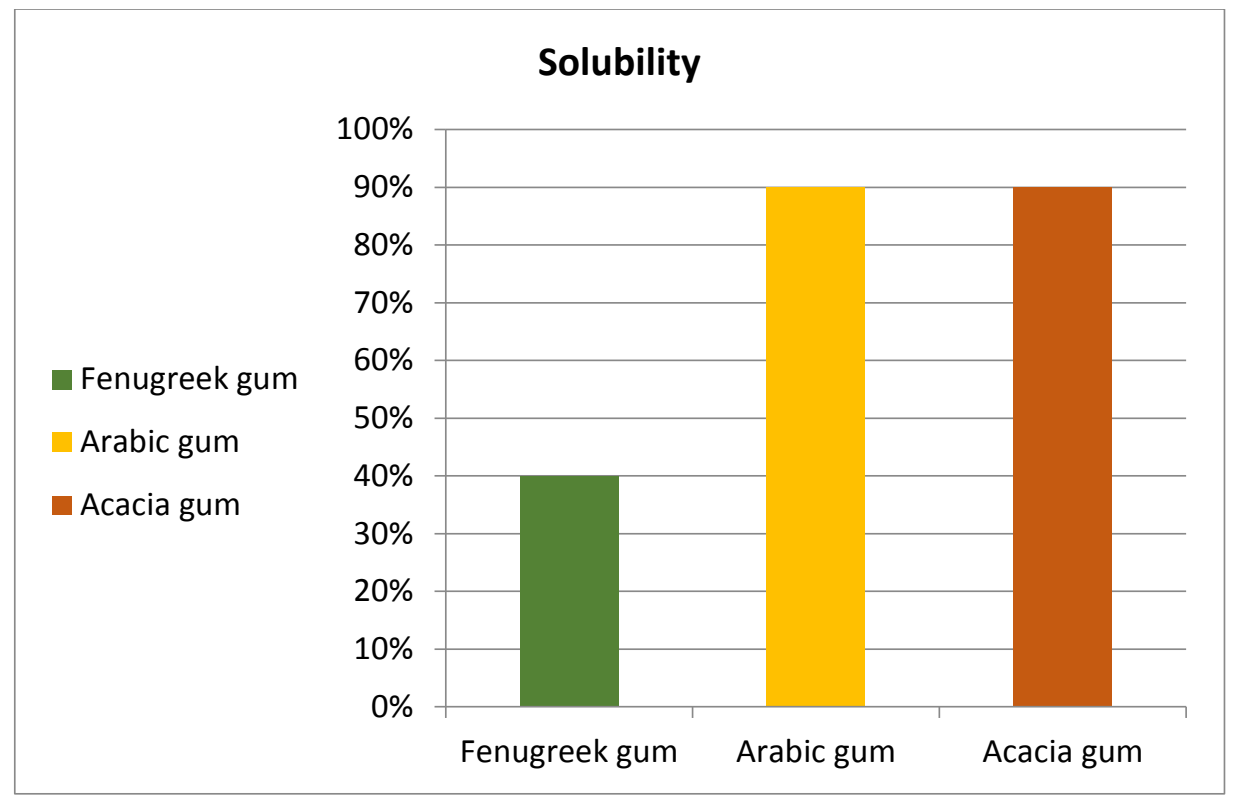

Fig. (3):The solubility of three different plant gum at $25^{\circ} \mathrm{C}(\mathrm{P}<0.05)$.

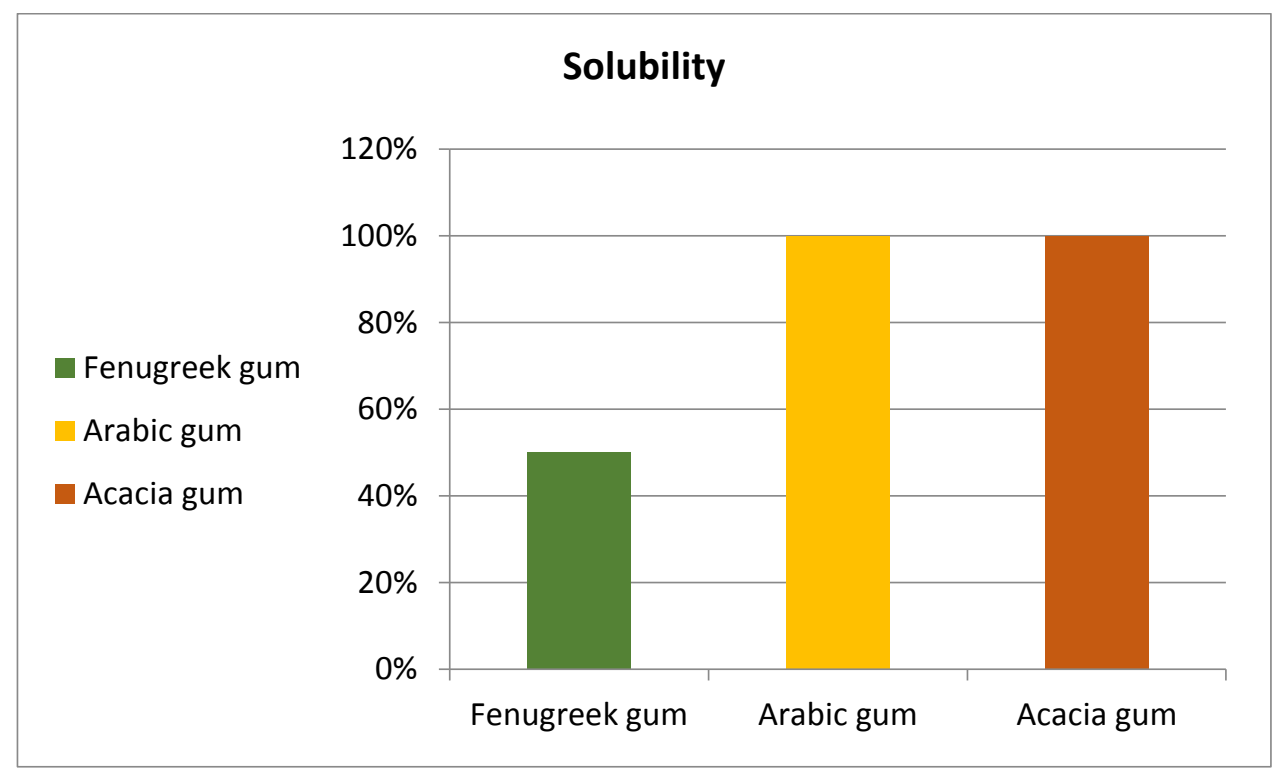

Fig. (4): The solubility of three different plant gum at $80^{\circ} \mathrm{C}(\mathrm{P}<0.05)$.

Effect of gums concentration on formation of gel

The results of table (2) indicated that the minimum concentration of Fenugreek gum which required to form a firm translucent gel was $1 \%$, while the maximum concentration of gum (4\%) was required to from a hard gel compared to Arabic gum and Acacia which did not formed the gel. These differences may be due to the Fenugreek gum which had high swelling index to produce gels or highly viscous solutions (Amid \& Mirhosseini, 2012) compared to the Arabic gum and Acacia with lower swelling index (Masuelli, 2013).

\section{Effect of temperature on the formation of gels}

The results of table (3) indicated that the gels were formed at concentration 1, 2, 3 and $4 \%$ of Fenugreek gum, Gum formed astrong gel at $4^{\circ} \mathrm{C}$, while the gels formation decreased at temperatures $20-100^{\circ} \mathrm{C}$. The decreasing of gels formation could be attributed to the impact of the temperature on the bonds responsible for maintaining the gel structure (Chidewe, 2004). 
Al-Shammari et al. / Basrah J. Agric. Sci., 32 (Special Issue): 217-227, 2019

Table (2): Effect of gums concentrations on the formation of gels.

\begin{tabular}{cccc}
\hline Concentration of gums $(\%)$ & Fenugreerk seed gum & Arabic gum & Acacia gum \\
\hline 1 & + & - & - \\
\hline 2 & + & - & - \\
\hline 3 & ++ & - & - \\
\hline 4 & +++ & - & - \\
\hline $5-10$ & - & - & - \\
\hline
\end{tabular}

Table (3): Effect of temperature on the formation of gel.

\begin{tabular}{|c|c|c|c|c|c|c|c|}
\hline \multirow{7}{*}{ Fenugreerk gum } & \multirow{3}{*}{$\begin{array}{c}\text { Concentration } \% \\
1\end{array}$} & \multicolumn{6}{|c|}{ Temperature $\left({ }^{\circ} \mathrm{C}\right)$} \\
\hline & & 4 & 20 & 50 & 70 & 90 & 100 \\
\hline & & + & - & - & - & - & - \\
\hline & 2 & + & - & - & - & - & - \\
\hline & 3 & ++ & - & - & - & - & - \\
\hline & 4 & +++ & - & - & - & - & - \\
\hline & $5-10$ & - & - & - & - & - & - \\
\hline Arabic gum & $1-10$ & - & - & - & - & - & - \\
\hline Acacia gum & $1-10$ & - & - & - & - & - & - \\
\hline
\end{tabular}

The Arabic gum and Acacia did not formed the gel at all different temperature. These results were in agreement with Chidewe (2004).

\section{Effect of pH}

The results of table (4) indicated that the fenugreek seeds gum is not able to form a gel at $\mathrm{pH}$ values 3-5. The can be attributed to the fracture of polysaccharide galactomannan. Therefore values of the below and the above of 7 do not have gel, and this is due to the possibility of partial depolymerization of the galactomannan loss of viscosity and weak gum susceptibility to gel formation (Norbrillinda et al, 2014).

The formation of firm gels increased when $\mathrm{pH}$ was raised from 6 to 7 , while the gel formation decreased at $\mathrm{pH} 10$; the gum molecules in solution would be negatively charged and experiencing repulsive force against each other, such that the aggregation of the gum chains for gels formation would not be promoted (Chidewe, 2004); The Arabic gum and Acacia did not form the gel at all different values of $\mathrm{pH}$ because they had lower swelling index. This might be resulted high solubility 90\% (Masuelli, 2013) .The results were in agreement with Chidewe (2004).

\section{Effect of calcium chloride and EDTA}

Table (5) represents that the decreasing of formation of gels fenugreek gum when calcium chloride was added at concentration 5-20 mM, Addition of calcium chloride at increasing concentrations to the gel forming suspensions of the gum, could have resulted 
Al-Shammari et al. / Basrah J. Agric. Sci., 32 (Special Issue): 217-227, 2019

Table (4): Effect of pH on the formation of gels.

\begin{tabular}{|c|c|c|c|c|c|c|}
\hline \multirow[t]{3}{*}{ Material } & \multirow[t]{3}{*}{ Concentration $\%$} & & & & & \\
\hline & & \multicolumn{5}{|c|}{$\mathbf{p H}$} \\
\hline & & 3 & 5 & 6 & 7 & 10 \\
\hline \multirow{5}{*}{$\begin{array}{c}\text { Fenugreerk } \\
\text { gum }\end{array}$} & 1 & - & - & _ & + & - \\
\hline & 2 & - & - & + & + & - \\
\hline & 3 & - & - & + & ++ & - \\
\hline & 4 & - & - & ++ & +++ & - \\
\hline & $5-10$ & - & - & - & - & - \\
\hline Arabic gum & $1-10$ & - & - & - & - & - \\
\hline Acacia gum & $1-10$ & - & - & - & - & - \\
\hline
\end{tabular}

Table (5): Effect of calcium chloride on the gelation of aqueous suspensions of gums.

\begin{tabular}{ccccccccc}
\hline & $\begin{array}{c}\text { Concentration } \\
\%\end{array}$ & \multicolumn{7}{c}{ Concentration of calcium chloride (mM) } \\
\cline { 2 - 7 } Fenugreerk gum & & & 0.0 & 0.5 & 1.0 & 5.0 & 10.0 & 20.0 \\
\cline { 2 - 7 } & & & + & + & + & - & - & - \\
\cline { 2 - 7 } & 3 & + & + & + & - & - & - \\
\cline { 2 - 7 } & 4 & ++ & ++ & ++ & + & - & - \\
\cline { 2 - 7 } & $5-10$ & - & - & - & - & - & - \\
\hline Arabic gum & $1-10$ & - & - & - & - & - & - \\
\hline Acacia gum & $1-10$ & - & - & - & - & - & - \\
\hline
\end{tabular}

in aggregation of the gum molecules, giving rise to the formation of precipitates with poor water binding capacity (Chidewe, 2004). The results of table (6) indicated that the gel formation was decreased when EDTA was added at concentrations $10-50 \mathrm{mM}$, the decreasing of formation could be related to the salts which destroyed the hydrophobic bonds and hydrogen bonds which are responsible for maintaining the gel structure (Chang et al., 2017), whereas Arabic gum and Acacia did not form the gel when calcium chloride and EDTA were added. 
Al-Shammari et al. / Basrah J. Agric. Sci., 32 (Special Issue): 217-227, 2019

Table (6): Effect of EDTA on The gelation of aqueous suspensions of gums.

\begin{tabular}{ccccccccc}
\hline & \multicolumn{7}{c}{ Concentration $\%$} & \multicolumn{7}{c}{ Concentration of EDTA } & $(\mathrm{mM})$ \\
\cline { 2 - 7 } Fenugreerk gum & & & 0.0 & 10 & 20 & 30 & 40 & 50 \\
\cline { 2 - 7 } & 1 & + & - & - & - & - & - \\
\cline { 2 - 7 } & 2 & + & + & - & - & - & - \\
\cline { 2 - 7 } & 3 & ++ & ++ & + & & - & - \\
\cline { 2 - 7 } & 4 & +++ & +++ & ++ & + & - & - \\
\cline { 2 - 7 } & $5-10$ & - & - & - & - & - & - \\
\hline Arabic gum & $1-10$ & - & - & - & - & - & - \\
\hline Acacia gum & $1-10$ & - & - & - & - & - & - \\
\hline
\end{tabular}

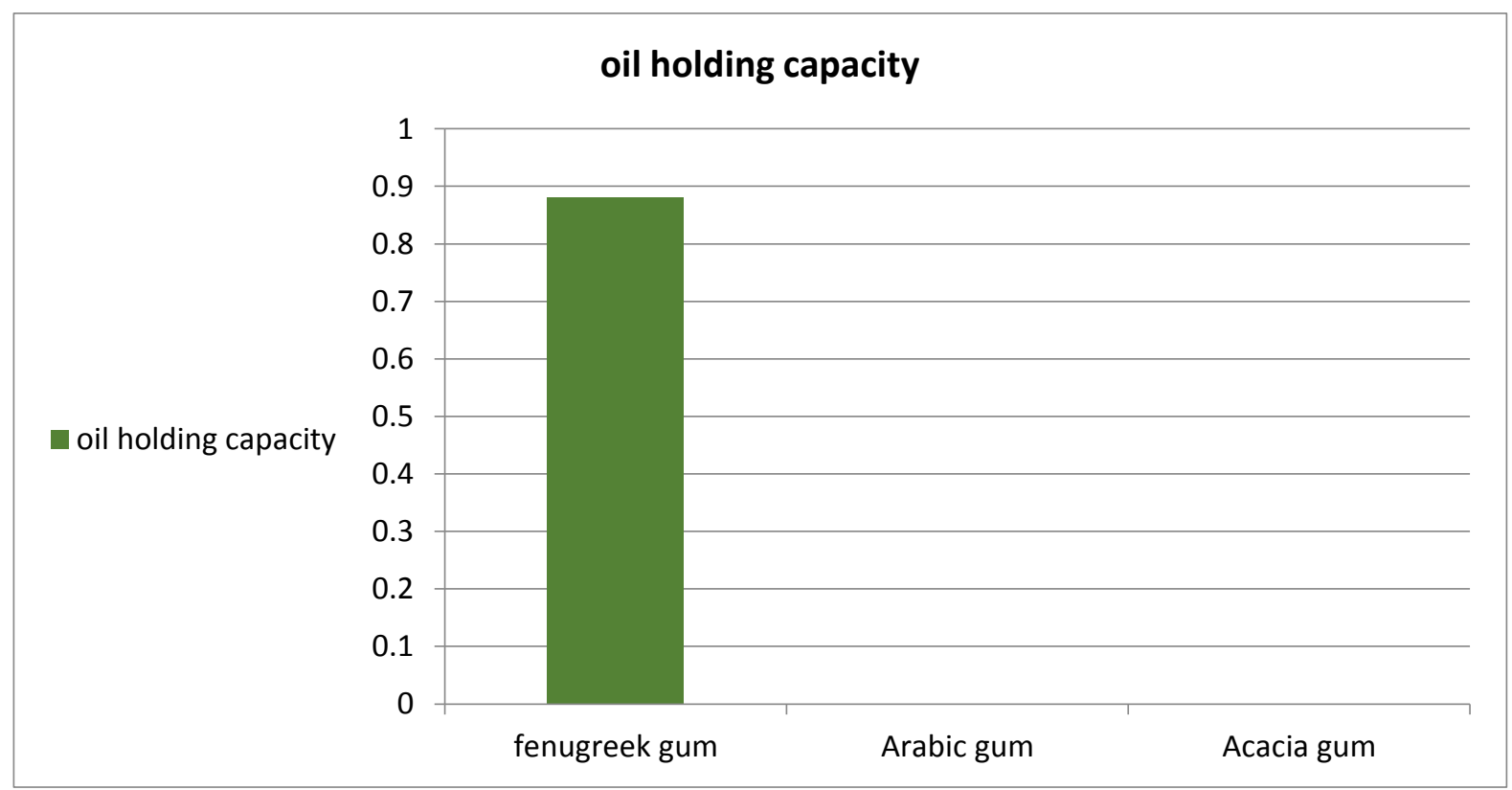

Fig. (5): The oil holding capacity of three different plant gum $P<0.05$.

Fig. (5) results showed that the oil holding capacity of Fenugreek gum was higher than the oil holding capacity of Arabic gum and Acacia $0,0 \mathrm{~g}$ oil. $\mathrm{g}^{-1}$ gum respectively) with average of $0.88 \mathrm{~g}$ oil $\mathrm{g}^{-1}$ gum. Fenugreek gum has high oil holding capacity because the presence of many nonpolar molecules in the crude gum such protein, that entrapment of the high amount of oil particles (Amid \&
Mirhosseini, 2012) compared with Arabic gum and Acacia did not had oil holding capacity because they were refined, many nonpolar molecules of gum that can trap high amount of oil particles; this property has a significant effect on food texture; for example, the high oil absorption in a meat product could help to reduce the losses of flavor and oil during the cooking of the meat (Thanatcha \& Pranee, 2011). 


\section{Conclusions}

Fenugreek gum has $\mathrm{pH}$ value (6.69) which is close to the neutral $\mathrm{pH}$ value (7). Fenugreek gum is partially soluble in cold water at $25^{\circ} \mathrm{C}$ and in hot water at $80^{\circ} \mathrm{C}$ lower compared to the standard Arabic gum and Acacia gum and Acacia; According to the Comparison of functional properties of Fenugreek gum with standard Arabic gum and Acacia, the Fenugreek gum had high swelling index and oil holding capacity than the Arabic gum and Acacia. The concentration of the Fenugreek gum, temperature, $\mathrm{pH}$ and adding $\mathrm{CaCl}_{2}$ and EDTA affected the gel formation of the fenugreeks gum, the increasing the gel formation with increasing of the gum concentration at $4 \%$ at $4^{\circ} \mathrm{C}$, whereas the gel formation was decreased when calcium chloride and EDTA were added at 5-20 mM and 20-50 $\mathrm{mM}$ respectively.

\section{Acknowledgements}

The authors would thank to staff of Food Science, Collage of Agriculture, University of Basrah for space and support the work.

\section{References}

Al- Janabi, A,A. \& Al-Abdullah, B.Y (2013). Study of physic chemical and functional properties of some plant gums and in corporate in The manufacture of jelly. J. Univ. Tikrit, 1(1): 103-112.

Amid, B.T. \& Mirhosseini, H. (2012). Effect of different purification techniques on the characteristics of hetero-polysaccharide protein biopolymer from durian (Durio zibethinus) seed. Molecules, 17: 10875-1089.

Bilal, S.; Dabo, M.; Momoh, D.B. \& Abubakar, S. (2015). Refining and Characterization of Gum Arabic using vacuum filtration method for application in oil and gas drilling fluid for mutation. J. Exp. Res., 3(2): 73-79.
Chang, Y.; Li, Y.; Miao, Q.; Jiang, H. \& Gao, X. (2017). Rheological properties f six plantbased seed gum. Am. J. Anal. Chem., 8: 690707.

Chidewe, C.K. (2004). Characterization of the polysaccharide material isolated from the fruit of Cordia abyssinica. Ph. D. Thesis. Univ. Zimbabwe: 208pp.

Farooq, U.; Malviya, R. \& Sharma, K. (2015). Design and development of muti particulate system for tavgeted drug drug delivery using Natural polymer. J. Pharmac. Acta, 6 (5): 1-8.

Gashua, I.; Ukekpe, S. \& Yusuf, I. (2013). Biophysical investigation of plant exudate of Acacia senegal (L) wild from Sudan-Savanrah ecological zone of Nigeria. . Int. J. Adv. Res, 1(4): 288-232.

Kumar, D.; Singhal, A.; Bansal, S. \& Gupta, S.K. (2014). Extraction, isolation and evaluation Trigonella foenum graecum as mucoadhesive agent for nasal gel drug delivery, J. NPA, 27(1): 40-45.

Kumar, R.; Patil, S.; Patil, M.B.; Patil, S.R. \& Paschapur, M.S. (2009). Isolation and evaluation of disinter grant properties of Fenugreek seed Mucilage. Int. J. PharmTech. Res., 4(1): 982-996.

Kay, B.A. (2016). The acute effect of soluble dietary fibre-enriched pudding production glycemic and lnsulinemic response in adults at risk for type 2. Ph. D. Thesis. Univ. Guelph:190pp.

Masuelli, M.A. (2013). Hydrodynamic properties of whole Arabic gum. Am. J. Food Sci. Tech., 1(3): 60-66.

Mundhe, M.R.; Pagore, R.R. \& Biyani, K.R. (2012). Isolation and evaluation of Trigonella foenum graecum mucilage as gelling agent in Diclofenac potassium gel Int. J. Ayurvedic \& Herb. Med., 2(2): 300-306. 
Nazni, P. \& Vigneshwar, P. (2014). Study on extraction and organoleptic evaluation of okra and hibiscus mucilage in corporate products. Int. J. Food Nutr. Sci., 3(1): 99-103.

Norbrillinda, M.T.; Anis, W.W.; Hamimi, I.A.; Madzlan, K. \& Shazlin, K. (2014). Effect of temperature and $\mathrm{pH}$ on viscosity of pineapple gum. Int. J. Trop. Agricul. Food Sci., 42(2): 143-148.

Repin, N. (2016). Investigations of mechanisms in voived in postprandial Glycemia Attenuation with dietary fiber consumption. Ph. D. Thesis. Univ. Guelph. pp:151.

Roberts, K.T.; Cui, S.W.; Change, Y.H.; Ng, P.K.W. \& Graham, T. (2012). The influence of fenugreek gum and extrusion modified fenugreek gum on bread. Int. J. Food Hydrocol., 26(2):350-358.

Thanatcha, R. and Pranee, A. (2011). Extraction and characterization of mucilage in Ziziphus mauritiana Lam. Int. Food Res. J., 18: 201202.

Verma, S.; Kumar, N. \& Sharma, P.K. (2014). Extraction and evaluation of Tvigonella foenum graecum L. \& Linum usitatissimum seed mucilage. Global J. Pharmacol., 8(4): 510-514.

Yusuf, A.K. (2011). Studies on some physicochemical properties of the plant gum exudates of Acacia senegal (Dakwara), Acacia sieberiana (Farar kaya) and Acacia nilotica (Bagaruwa). J. Res. Nat. Dev., 9: 10-17.

Sciarini, L.S., Maldonado, F., Ribotta, P.D., Pérez, G.T. \& León, A.E. (2009). Chemical composition and functional properties of Gleditsia triacanthos gum. Int. J. Food Hydrocol. 23: 306313. 